\title{
International Collaboration for Capacity Development in Higher Education Leadership and Management: the Uganda-Finland Initiative
}

\author{
Ronald Bisaso and Seppo Hölttä
}

\begin{abstract}
Changes in higher education leadership and management in sub-Saharan Africa have been epitomised by public sector reforms sanctioned by the World Bank since the beginning of the I990s. Recently, emerging forces redefining higher education have entailed country-specific development cooperation instruments in countries such as Finland, Norway, Austria and The Netherlands. The overriding emphasis is on the role of higher education institutions in the socio-economic transformation of developing countries, partly realisable through robust higher education leadership. However, sustainable academic and professional knowledge bases in the form of non-degree, masters and doctoral programmes to build such leadership and management capacity are elusive. Drawing on the Uganda-Finland capacity development initiative, a stakeholder analysis was conducted through document reviews. The findings and conclusions illuminate the complementary roles of stakeholders and the necessity of integrating professional career pathways into masters and doctoral higher education leadership and management programmes implemented through international collaboration.
\end{abstract}

Keywords: higher education leadership, development cooperation, capacity development

Les changements dans la direction et la gestion de l'enseignement supérieur en Afrique sub-saharienne ont été illustrés par des réformes du secteur public sanctionnées par la Banque Mondiale depuis le début des années

ABOUt THE AUthors: RONALD BISASOI Makerere University, Uganda E-mail: rbisaso@ cees.mak.ac.ug

SEPPO HÖLTTÄ University of Tampere, Finland. E-mail: seppo.holtta@uta.fi 
I990. Récemment, l'émergence de forces redéfinissant l'enseignement supérieur a engendré le développement par des pays comme la Finlande, la Norvège, l'Autriche et les Pays Bas d'instruments de coopération pour le développement spécifiques à chaque pays. L'accent a été mis sur le rôle joué par les institutions d'enseignement supérieur dans la transformation socio-économique des pays en voie de développement, rôle qui ne peut être réalisé sans une direction robuste. Cependant, il manque des bases de savoir académique et professionnel durables sous forme de cursus non diplômants, de masters et de doctorats, pour former de telles capacités de direction et de gestion. Une analyse des parties prenantes a été réalisée grâce à une revue de textes portant sur l'exemple de l'initiative Ouganda Finlande pour le développement des capacités. Les résultats et conclusions soulignent le rôle complémentaire des parties prenantes et la nécessité de professionnaliser les carrières de direction et de gestion de l'enseignement supérieur au moyen de masters et de doctorats établis à travers des coopérations internationales.

\section{Introduction}

Changes in higher education leadership and management in sub-Saharan Africa have been pervasive since the public sector reforms sanctioned by the World Bank atthe beginning of the I99os. Indeed, until recently the World Bank has been the major player in higher education development and policy shifts in Africa where the current emphasis is the knowledge economy driven by the 'innovation system' and 'partnerships'(Obamba, 20I3, pp. 83,95-IO2). In addition to international organisations' involvement, development cooperation in developing countries in Africa now entails new country-specific instruments for higher education. Examples include Finland's Higher Education Institutions Institutional Cooperation Instrument; the Austrian Partnership Programme in Higher Education and Research for Development; the Norwegian Programme for Capacity Building in Higher Education and Research for Development; The Netherlands Organisation for International Cooperation in Higher Education and its sub-programme The Netherlands Initiative for Capacity Development in Higher Education; the Swedish International Development Agency; Germany's Partnerships with Higher Education Institutions in Developing Countries and many others. The overarching focus of these development cooperation frameworks is to support poverty reduction strategies. This is partly a response to concerns raised by the Association of Commonwealth Universities in 20 Io which castigated international donors for not paying sufficient attention to the capacity of higher education to contribute to social change. Ordinarily, higher education institutions contribute to research and the development of sub-Saharan African countries (Bloom, Canning, 
Chan and Luca, 20I4). For example, graduates can enhance an economy's competitiveness by participating in entrepreneurial activities, while different business entities harness knowledge and innovations for possible uptake by different economic sectors. Clearly, for development cooperation to achieve the target of addressing the socio-economic asymmetries on the continent through higher education, leadership and management would play a crucial role in promoting the interface with society (Bisaso 20I0; Cloete, Bailey, and Maassen, 20II; Meek, Goedegebuure, Santiago, and Carvalho, 20I0). Indeed, as Saint (2004, p.64) argues:

Today universities in Africa are much larger institutions, more complex in their working relationships with the external environment, and hard pressed to keep pace with the rapid changes in the world around them...Addressing the needs for leadership and management is...a necessary condition for meeting the other challenges faced by African universities.

Unfortunately, the leadership and management of universities in subSaharan Africa, is weak, inefficient, and bureaucratic and has inadequate capacity to articulate the knowledge economy discourse (Cloete et al., 2oII; Teferra and Altbach, 2004). Additional challenges include a weak vision for leadership development, a lack of qualified staff in leadership/management positions as well as succession plans, inadequate financial and infrastructural resources, and a lack of structural and systematic training/skills development programmes (Bakuwa and Mouton, 20I5; Hoba, $\mathrm{Mba}$ and Alemneh, 20I3).While training in leadership and management in universities in sub-Saharan Africa commenced more than two decades ago and is on-going, most initiatives have not been harmonised for complementary benefits as they emerge in the respective countries (Mouton, Effah and Sibuga, 20I5). In the case of Uganda, the Management and Leadership Programme implemented by the higher education regulatory body came to an end without mechanisms for sustainability after the funding period (Olupot, Achanga and Kasozi, 20I5). Overall, it is apparent that strong professional and academic programmes on higher education that specialise in leadership and management are non-existent or fragmented (Centre for Higher Education Transformation [CHET], 2006; Cutright, 20I0), with a few exceptions including University of KwaZulu-Natal, University of the Western Cape and the Uganda Management Institute.

International partnerships are one of the ways through which higher education as a relatively young field of professional study can be initiated and grow in sub-Saharan Africa (Ssentamu, Ezati, Bisaso, Hölttä, and Pekkola, 20I4). Such partnerships entail the development of knowledge bases in the form of non-degree, masters and doctoral programmes in leadership and management as a sustainable mechanism for capacity development. 
Such leadership has often been interpreted in terms of institutional and departmental positions. However, in terms of capacity development, and in line with Juntrasook's (20I4) view, leadership is shifting from heroic to post-heroic dimensions that entail performance, professional practice and professional role modelling, hence becoming more shared or distributed. At the same time, what constitutes or reflects good leadership may differ according to disciplinary fields (Kekale, I999). For many years, leadership and management of higher education institutions in Africa has been restricted to the activities of executive management, especially the vicechancellor. More recently, principals, deputy principals, registrars, deans and deputy deans and heads of departments have been included (Bakuwa and Mouton, 20I5).

Taking a different approach to capacity building in leadership and management in higher education, this article examines the initiation and institutionalisation of a leadership and management programme in a higher education institution in Uganda through international collaboration funded by the Higher Education Institutions Institutional Cooperation Instrument of Finland. It highlights the use of a multiple stakeholder approach in clarifying the need for and the execution of a capacity development initiative jointly implemented by higher education institutions in Uganda and Finland. Moreover, it emphasises doctoral students' involvement in the initiative as one of the measures to ensure sustainability.

\section{Overview of trends in Capacity Development}

Capacity development has been associated with international collaboration and has become part of development cooperation (Brinkerhoff and Morgan, 20I0) as well as an instrument to sustain policy changes involving the transition from state to market-oriented public sector reforms (Dill, 2000). Therefore, international development cooperation can be explored as a form of internationalisation of higher education. The instruments for development cooperation in higher education can be broadly understood as: a) institutional capacity building that may comprise of organisational development, curriculum and pedagogical development, leadership and management, and infrastructure development to mention but a few, and b) human capacity building that is associated with skills development for university administrators, and exchange programmes for students and lecturers, among others (Koehn, 2013).

Over the years, capacity development has mainly entailed international research cooperation but it has remained conceptually ambiguous and there are few empirical studies on this phenomenon (Brinkerhoff and Morgan, 20I0; Dill, 2000). Moreover, it is not clear whether international collaboration and academic partnerships have indeed contributed to the 
transformation of the university organisation in order to make a meaningful contribution to socio-economic development.

For the purposes of this article, the Organisation for Economic Cooperation and Development (OECD) (2006) conception of capacity development is adopted: "the process whereby people, organisations, and society as a whole unleash, strengthen, create, adapt, and maintain capacity over time" (p.I2). This denotes a systemic approach that includes individuals, organisations and the broader environment and relationships. Moreover, as noted by the OECD (2006), capacity development requires sufficient time for uptake. As Gmelch (I999, p. 78) asks: "if it takes seven to fourteen years to achieve expertise in our academic disciplines, why do we assume we can create an academic leader with a weekend seminar?" This question is partly explored in this article by examining the development of sustainable knowledge bases in the form of professional and academic programmes.

Finally, one of the key features of the World Bank Education Strategy 2020 is the emphasis on multi-stakeholders' involvement in capacity development in education (World Bank, 20II). This implies the need for a systemic approach so that the outcome is co-owned by a range of stakeholders with the added advantages of stronger decision making and accountability (Brinkerhoff and Morgan, 20I0; Obamba, 20I3).It is increasingly apparent that funding for international cooperation activities is conditioned by the composition and complementary roles of the stakeholders involved.

\section{The open system and institutional theories as interpretive frameworks}

The open system theory postulates that organisations influence and are influenced by changes in their external environments. Changes may originate in local or global environments. As open systems, organisations survive by continually sensing such changes and adapting to changing conditions in the complex environment. Open systems have permeable boundaries that permit several interactions between the environment and elements of the system. Changes in the environments of open systems are unpredictable, the internal organisational structures are flexible and the internal organisational processes are nonlinear. Hence, the symbiotic relationship with the environment generates feedback which may be received by the organisation or its subunits as new input and becomes part of the cycle that eventually seeks new responses or strategies to generate new output.

This article also draws on the institutional theory to interpret the institutionalisation of leadership and management programmes through international collaboration. This theory postulates that organisations survive by conforming to environmental pressures that in most cases take the form of rules and belief systems. This suggests that individual organisations reorganise their inner structures in order to survive (Scott, I995). 
The institutional theory can be anchored on the five strategies identified by Oliver (I99I) that individual organisations use to respond to change based on the assumption that, in most cases, responses will differ. These variations are largely related to the profiles, missions and visions of the individual organisations, in this case, higher education institutions. Oliver's (I99I) general five strategies are as follows:

a. Acquiescing: This strategy emphasises conformity to pressures in the environment.

b. Compromising: The main focus is negotiating to find a balance between institutional pressures and an organisation's responses. This is more evident in conflict-ridden environments.

c. Avoidance: This strategy entails buffering the organisation from the effects of institutional pressures. Emphasis is placed on the need to decouple structures from activities to ensure that external demands or rules that are in most cases controversial and universal are better served.

d. Defiance: Organisations that are defiant have been reported to resist pressure in a very public manner. This is evident when an organisation's norms and interests deviate significantly from those required by the external environment (Scott, I995).

e. Manipulate: This involves an organisation co-opting, influencing or even controlling the environment. This can be achieved by developing linkages to important sources of power. Organisations that adapt this strategy gain legitimacy by creatively building and sustaining their images (Scott, I995).

The two frameworks are applied in the context of international collaboration. It is argued that higher education institutions in this partnership were affected by changes in the local and global environment in a reciprocal manner. Other stakeholders such as funding agencies, ministries and other policy level entities influenced the processes within the participating institutions. By ensuring that some of the external pressures are addressed, higher education organisations reorganised internally. Similarly, given the actions of and reports from the universities, other stakeholders have been affected. It is important to note that external requirements and interests have been integrated into organisational processes and structures through a range of measures to ensure sustainability; the institutional theory sheds light on this.

\section{Experiences of a Uganda-based capacity development project Finland's Higher Education Institutions Institutional Cooperation Instrument}

This funding instrument is anchored in Finland's development policy and 
its main goal is to eradicate poverty and promote sustainable development. The programme creates a mechanism through which higher education institutions in Finland cooperate with their counterparts in developing countries to enact institutional reforms. It is expected that the projects under this programme will focus on capacity development in the developing countries in the areas of administration, pedagogy and support for institutional development plans. A major feature of this programme is that "[cooperation] between Finnish and developing country institutions shall be based on needs defined by the developing country universities, and built on the principles of mutual learning" (Ministry for Foreign Affairs, 20Io, p.4). It thus emphasises the institutionalisation of knowledge, bringing young experts/scholars on board and exploring the potential of information and communication technology for cost effective and efficient capacity development. The programme commenced in 20II. In the first round (June 20II-December 20I2), I5 projects were funded and implemented. Twenty-three projects were funded for three years until December 2015 . The total budgetary allocation for the projects, with a focus on Africa, was I5.4 million Euros (Ministry for Foreign Affairs, 20I4).

The Centre for International Mobility is responsible for the administrative coordination of the programme while the Department of Development Policy at the Ministry for Foreign Affairs has overall management responsibility. Despite this systematic approach to capacity development, an evaluation report notes that, as much as the programme is "an effective institutional strengthening tool ... it is significantly limited by the relatively short project duration and the exclusion of research capacity building activities" (Ministry for Foreign Affairs, 20I4, p.8). Consequently, it has been recommended that it merges with other programmes such as the NorthSouth-South mobility programme and that research should be funded by the Academy of Finland. This would promote a comprehensive, long term, well-funded and prioritised capacity development instrument as well as inter-linked activities for partner countries.

\section{The Building Institutional Capacity for Training Leadership and Manage- ment in Ugandan Universities (LMUU) Project}

Consistent with the focus of Finland's Higher Education Institutions Institutional Cooperation Instrument, the LMUU project was conceived in line with priorities identified by the Uganda Management Institute which sought to build its institutional capacity to develop leadership and management in the country's higher education sector. Since no such programmes were in place, and given the importance of sustainable knowledge bases, the first step involved consultation with local stakeholders.. The need to professionalise higher education leadership and management in Uganda 
was raised in the Report of the Visitation Committee to Public Universities which found that weak leadership and management in this sector hampered universities from promoting national economic development (Government of Uganda, 2007). These findings were further reinforced by Bisaso (20I0; 20II), whose study pointed to the need to build management capacity at Makerere University. The overall objective of the LMUU project was: to build responsive capacities of Ugandan universities for engagement in national development. The specific objectives were to: a) train, retool and equip academic staff at the Uganda Management Institute in partnership with academic staff at the School of Education in Makerere University with skills and new knowledge of higher education and the theoretical and practical dynamics of university leadership and management; b) jointly develop a diploma programme on university leadership and management at the Institute to strengthen its capacity to train and build competences for professional management and leadership of higher education institutions in Uganda and East Africa; and c) pilot the developed content of the accredited diploma by engaging academic staff from the Institute and Makerere University in team teaching and peer evaluation.

Sustainability would be promoted through existing doctoral studies in higher education management, poverty reduction and social change at the Higher Education Group, University of Tampere in Finland. The areas of academic research included building management capacity, the role of higher education in poverty reduction, and institutionalisation of the "third mission' in different higher education systems in Africa. The research findings of doctoral graduates from such programmes could be applied to build capacity in developing countries.

\section{A multi-stakeholder approach}

In order for the Finnish partners to appreciate the situation on the ground, representatives of the Universities of Tampere and Helsinki undertook a preparatory visit to Uganda. The team comprised of two professors and a doctoral researcher. Meetings were held with key stakeholders to ascertain their views on the proposed project. The stakeholders included the Director, Higher Education at the Ministry of Education and Sports in Uganda, the Director and staff of the National Council for Higher Education, which is the quality assurance and accreditation agency in Uganda, and the leadership and selected academic staff at the Uganda Management Institute and the School of Education, Makerere University. Other stakeholders included officials at the Embassy of Finland in Nairobi and representatives of the Inter-University Council for East Africa. The latter was included in order to ensure that, should the project go ahead, it would serve the East African region in line with the Council's higher education strategic plan (2006/07- 
20Iо/ІІ). This plan emphasised the need to strengthen the leadership and management capacities of its member universities in Uganda, Kenya, Tanzania, Rwanda and Burundi. Similarly, as the regional representative of the Finnish Ministry for Foreign Affairs, the Embassy was consulted to ensure that the intervention would complement other activities funded by the Government of Finland. The Uganda Management Institute worked in partnership with Makerere University School of Education, and the Universities of Tampere and Helsinki to formulate the project that was announced in December 20Io. The project was in line with the goals of the Strategic Plan for Higher Education 2003-2015 whose focus is "enhanced quality and relevance, efficient and effective higher education, and improved governance and management in higher education in Uganda by 20I5" (Ministry of Education and Sports, 2003,p.4).

Broad stakeholder engagement ensured consensus on the overall proposal, with specific responsibilities based on expertise assigned to key partners. For instance, although both the Higher Education Group at the University of Tampere and the Uganda Management Institute were involved in teaching and research on higher education, the former dealt with its theoretical and conceptual underpinnings, while the latter specialised in practical institutional management and leadership. Similarly, academic staff from the School of Education at Makerere University had expertise in curriculum development. Cooperation among the partner institutions created opportunities for mutual learning, interdependence and a plurality of ideas to enrich project activities.

The project focused on three interrelated activities: a) training of trainers b) curriculum development for the post graduate diploma in higher education leadership and management and c) piloting the developed content of the accredited post graduate diploma through team teaching and peer evaluation by the trained academic staff. These activities were carried out through seminars, workshops, self-study, group assignments, and distance learning, among others. The theoretical and conceptual content was based on the syllabus of the Study Programme in Administration and Management of Higher Education at the Higher Education Group, University of Tampere. The syllabus from the Finnish university included five modules: (i) Introduction to Research on Higher Education, (ii) Higher Education Systems - Steering and Coordination Mechanisms, (iii) Organisation, Decision Making, Management and Leadership, (iv) Finance and Financial Administration, and (v) Quality and Quality Assurance.

In the first instance, 25 prospective trainers received training on the five modules. The trainees were mainly academic staff from Makerere University (Schools of Education and Gender and Women Studies) and the Uganda Management Institute that were selected based on their diverse 
but complementary expertise ranging from curriculum development, to foundations of education, and gender studies, among others. They were introduced to the theoretical and conceptual aspects of higher education leadership and management over a period of six months to enable them to contribute to the development of the curriculum and pilot teach the content of the accredited curriculum in preparation for actual teaching in the post graduate diploma programme. In order to link the project to changes at the policy level, the Ministry of Education and Sports in Uganda recommended that two experts at the Directorate of Higher, Technical, Vocational Education and Training participate in this phase.

Multi-stakeholder involvement was also evident in the selection of facilitators for the training of trainers' workshops. Staff from the Universities of Tampere and Helsinki in Finland presented the theoretical and conceptual aspects of the five modules. In the same vein, facilitators from the Association of African Universities/the African Union Commission and the African Development Bank offered insights on developments in higher education on the African continent. Facilitators were also drawn from the Inter-University Council for East Africa, the Uganda National Council for Higher Education, the Ministry of Education and Sports in Uganda, and top leadership of the country's higher education institutions. International, regional, national and institutional perspectives were thus covered. The trainees' assignments during the training phase included case studies of Ugandan universities which strengthened their understanding of the competences required by leadership and management in the African context. They provided valuable feedback for improvements in the content and its delivery.

Secondly, the content and instructional materials for the diploma programme were jointly developed by Finnish experts and the 25 trained Ugandan experts. The content of the training of trainers' modules provided some of the core modules on higher education leadership and management. The theories and concepts were thus adapted to suit the needs of the Uganda Management Institute. A module titled Higher Education and Sustainable Development was added to the five core modules that had been taught, with the aim of broadly addressing issues relating to poverty reduction. Another module that related to the sub-Saharan African context was an elective titled Gender in Higher Education. A stakeholders' workshop was organised by the Uganda Management Institute to determine whether the draft curriculum met the needs of all stakeholders, including government ministries, national agencies like the Uganda National Council for Science and Technology, international agencies such as the Uganda National Commission of UNESCO and leaders and managers of higher education institutions. Thereafter, the revised curriculum was forwarded to the 
respective organisational structures of the Uganda Management Institute for approval and thereafter to the Uganda National Council for Higher Education (UNCHE) for accreditation. The post graduate diploma programme in higher education leadership and management was accredited as a professional programme by the UNCHE in July 2012 for a period of five years.

Third, team teaching and peer-evaluation by Finnish experts and Ugandan trainers was conducted to determine the capability of the 25 trainees to teach the content of the accredited programme. They were required to prepare a lecture on a given topic in any accredited course and teach it as a team (in most cases to those that had been involved in drafting the module). They then received feedback. After an open call for applications, I2 fee-paying students were admitted to the diploma programme. The programme was thus self-sustaining after the development cooperation funding period ended. The first cohort graduated in March 20I4 and the second and third cohorts have been admitted, with teaching offered by those that participated in the different phases of the LMUU project activities.

\section{Challenges}

Several challenges were encountered in executing the project. In the first place, trainees had full-time academic positions and assignments/assigned readings were not their core focus. This necessitated several reminders since the training in higher education leadership and management was not directly related to some of the content they were teaching at their respective institutions. One of the ways in which this challenge was addressed was allocating assignments and modules in line with trainees' expertise. For instance, teachers of foundations of education worked on the foundations of higher education module. Curriculum overload was another challenge as post graduate students at the Institute were required to take certain basic modules that were not necessarily related to studies on higher education leadership and management. Given the institutional requirements, the implementers of the LMUU project had to work within the parameters even if this meant content overload for prospective students. Finally, the LMUU project and similar projects require effective, sustainable quality assurance mechanisms. This would entail the development of facilitators' manuals for trainees as they implement the accredited curriculum. While this was not included in the initial phase, the first priority of the second phase (the LMUU II project) was to entrench sustainable quality assurance in the diploma programme already in operation by developing systematic module handbooks for use by facilitators. 
Relevance of doctoral studies and research in the capacity development project The goals of the LMUU project were aligned with doctoral research conducted by the Higher Education Group at the University of Tampere. In clarifying Uganda's capacity needs, it was found that two doctoral dissertations on the country's higher education sector had focused on management capacity building (Bisaso, 2OII) and institutionalisation of the 'third mission' (Mugabi, 20I4). Some of the findings and recommendations from one of these studies were applied during the training and the development of the modules in the post graduate diploma in higher education leadership and management at the Uganda Management Institute. Similarly, a doctoral dissertation was completed on the role of higher education in poverty reduction strategies in sub-Saharan Africa with a focus on Cameroon (Doh, 20I2). The graduate was actively involved in capacity building in Uganda and the inception of a similar capacity development initiative in Cameroon. As a result, a network was created of expertise on higher education leadership and management aligned to the career paths of doctoral students. Indeed, all three doctoral students taught and participated in the development of the curriculum on leadership and management in Uganda. One was the project manager from inception of the project, coordinating and liaising with the partners in addition to deepening his own understanding of the day-to-day dynamics of higher education leadership and management. Hence, the implementation and potential sustainability of the capacity development project can be partly attributed to the link between doctoral research and the graduates' prospective careers.

Finally, following the end of the funding period for the project, the Ministry for Foreign Affairs supported a three-year project with more partners in sub-Saharan Africa. Strengthening Institutional Capacity for Higher Education Leadership and Management in sub-Saharan Africa (LMUU II) (2013-2015) was an institutional capacity building project among five higher education institutions, namely, the Uganda Management Institute, Makerere University, University of KwaZulu-Natal, and the Universities of Helsinki and Tampere, with the last-mentioned acting as the coordinating partner. The LMUU II project built on some of the outputs of the LMUU project (2OII-2OI2) reported in this article.

\section{Discussion and Conclusion}

This article highlighted the relevance of international collaboration in the transformation of higher education leadership and management in the Ugandan context, using an institutional capacity development project funded by Finland's Ministry for Foreign Affairs as a case study. Rather than focusing on actual changes in the practice of leadership and manage- 
ment, it examined the development of a professional field of study and its adaptation to an African context.

It has been argued that a multi-stakeholder approach should be adopted to clarify the need for and execution of capacity development projects. It is also important that such training programmes are internationally comparable in terms of theoretical and conceptual rigour. A number of points for discussion emerge from the article.

First, the project emphasised the role and relevance of multiple stakeholders at various levels. This systemic approach (Brinkerhoff and Morgan, 20I0; OECD, 2006; World Bank, 20II) can be interpreted using the open system theory. Experiences in the first phase of the project highlight the importance of identifying and adapting to changes in the environment. The Finnish government funding programme has limitations and presents quite serious boundary conditions for project implementation. Another essential ingredient in the success of the project was innovative adaptation to address the emerging challenges at different stages of project implementation based on trust and transparency among the northern and southern partners.

Second, the environment that the Uganda Management Institute operated in was as global as it was local and it presented pressures for change to which it had to respond. In response, the Institute invoked some of the institutional strategies identified by Oliver. For instance, acquiescing is evident in its acceptance of the views of the stakeholders and the national strategy on higher education given its key role as a management development institute in Uganda. Compromising was equally visible in negotiations with all partners on the content of the programme, and the appointment of academic staff from Makerere University trained under the first phase of the project to work as Associate Consultants at the Institute. In the same way, avoidance was evident in the inclusion of basic modules in the curriculum of the post graduate diploma in higher education leadership and management, but these needed to be considerably adapted to make them relevant to prospective students. Furthermore, the Uganda Management Institute ensured that the diploma programme went through all the established quality assurance mechanisms at institutional level. Furthermore, there was manipulation to the extent that multiple stakeholders were involved, especially the Ministry of Education and Sports and the Uganda National Council for Higher Education to ensure that the programme is relevant to the needs of higher education leaders and managers in the country. This was achieved through clarification of needs, guest lectures and the Ministry's representation on the Project Steering Board.

Third, the article highlighted the relevance of doctoral research in capacity building. While this was a new dimension that was perhaps not anticipated 
by the funding agency, the value added was evident. Along similar lines, the evaluation of the development cooperation instrument by Finland's Ministry for Foreign Affairs promoted the integration of research capacity building. However, it is recommended that the Ministry further examines some of the approaches adopted in doctoral training and integrates professional career pathways into masters and doctoral higher education leadership and management programmes implemented through international collaboration. This would enable the development of best practices.

One of the weaknesses of the Finnish capacity development programme is that it does not permit reallocation or allocation of funds to any complementary research activity, whether planned or emergent. The link between capacity building and doctoral training envisaged in the revised funding instrument is an important step in addressing this weakness. Another impediment was the restriction on South-North mobility which was also articulated in the development cooperation guidelines. These two issues were highlighted in the Ministry for Foreign Affairs' Evaluation Report of June, 20I4 and will hopefully be addressed in the succeeding funding phases.

In conclusion, international collaboration is a critical lever in add-ressing the challenges of higher education leadership and management in sub-Saharan Africa and Uganda in particular. This is a form of internationalisation largely at home which calls for the involvement of multiple stakeholders at all levels to ensure acceptability, effective decision making and accountability. Moreover, there is need to comply with existing institutional frameworks despite the constraints they may present. The importance of doctoral studies and research in capacity development was highlighted in order to promote the sustainability of the outcomes of such partnerships and it should be systematically entrenched in the future.

\section{References}

Bakuwa, J. and Mouton, J. (2015). A review of the scholarship on HELM training in Africa. In J. Mouton and L. Wildschut (Eds.). Leadership and Management. Case studies in training in higher education in Africa (p.3-16). Cape Town: African Minds.

Bisaso, R. (20I0).Organisational responses to Public Sector Reforms in Higher Education in Uganda: A Case Study of Makerere University. Journal of Higher Education Policy and Management 32 (4), 343-351

Bisaso, R. (20II). Utilising the learning organization for management capacity building at Makerere University. Tampere: School of Management, University of Tampere, Finland.

Bloom, D.E., Canning, D., Chan, K., and Luca, D.L. (20I4). Higher education and economic growth in Africa. International Journal of African 
Higher Education 1 (1), 23-57.

Brinkerhoff, D. W. and Morgan, P.J. (20I0). Capacity and capacity development: coping with complexity. Public Administration and Development 30(1), 2-10.

CHET (2006).An approach to developing higher education as a field of study in Africa. Cape Town: Centre for Higher Education Transformation (CHET).

Cloete, N., Bailey, T., and Maassen, P. (20II). Universities and Economic Development in Africa: Pact, academic core and coordination. Synthesis report. Cape Town: Centre for Higher Education Transformation (CHET).

Cutright, M. (2010). Expanding access and quality in Uganda: The challenges of building a plane while flying it. International Education 40 (1), 21-31.

Dill, D. D. (2000). Capacity building as an instrument of institutional reform: Improving the quality of higher education through academic audits in the UK, New Zealand, Sweden, and Hong Kong. Journal of Comparative Policy Analysis: Research and Practice 2(2), 2II-234.

Doh, P.S. (2012). The Responses of the Higher Education Sector in the Poverty Reduction Strategies in Africa. The Case of Cameroon. Tampere: Higher Education Finance and Management Series, Higher Education Group/ Tampere University Press.

Gmelch, W.H. (I999). Building leadership capacity for institutional reform. Proceedings of the Inaugural Conference of the Global Consortium of Higher Education and Research for Agriculture, Ames, Iowa: Iowa State University, 77-84.

Government of Uganda (2007). Uganda Government Visitation Committee to Public Universities, Kampala: Ministry of Education \& Sports.

Hoba, P., Mba, J. and Alemneh, T. (2013). Sub-Saharan Africa Higher Education Leadership Development (SAHEL) Study Report. Accra: Association of African Universities

Juntrasook, A. (20I4). 'You do not have to be the boss to be a leader': contested meanings of leadership in higher education. Higher Education Research and Development 33 (1), 19-31.

Kekale, J. (I999). 'Preferred' patterns of academic leadership in different disciplinary(sub) cultures. Higher Education 37 (3), 2I7-238.

Koehn, P. (2013). Donor-supported transnational higher education initiatives for development and research: a framework for analysis and a call for increased transparency. Higher Education Policy. 26 (4), 349-372

Meek, L. V., Goedegebuure, L., Santiago, R., and Carvalho, T. (Eds.). (20I0). The changing dynamics of higher education middle management. Dordrecht: Springer. 
Ministry for Foreign Affairs(2010). Higher education institutions institutional cooperation instrument (HEI-ICI). Helsinki: MFA.

Ministry for Foreign Affairs (20I4).Evaluation of Finland's support to higher education institutions - North-South-South and HEI-ICI. Semi-Final Draft Report. Helsinki: MFA

Ministry of Education and Sports (2003).The Strategic Plan for Higher Education 2003-2015. Kampala: Ministry of Education and Sports.

Mouton, J., Effah, P., and Sibuga, P.K. (20I5). The context of HELM training in Africa. In J. Mouton and L. Wildschut (Eds.). Leadership and Management. Case studies in training in higher education in Africa (p.I7-35). Cape Town: African Minds.

Mugabi, H. (20I4). Institutionalisation of the 'Third Mission' of the University. The case of Makerere University. Tampere: Tampere University Press.

Obamba, M. O. (2013). Uncommon knowledge: World Bank policy and the unmaking of the knowledge economy in Africa. Higher Education Policy 26 (I), 83-108.

OECD (2006). The challenge of capacity development: working towards good practice. Paris: OECD.

Oliver, C. (I99I). Strategic responses to institutional processes. Academy of Management Reviewi6 (I), I45-I79.

Olupot, E., Achanga, P. and Kasozi, A. (20I5). Uganda. In J. Mouton and L. Wildschut (Eds.). Leadership and Management. Case studies in training in higher education in Africa(p.53-66). Cape Town: African Minds.

Saint, 2004).Comments on "challenges facing African universities". African Studies Review 47 (1), 61-65.

Scott, W.R. (I995). Institutions and Organizations. Thousand Oaks: Sage.

Ssentamu, N.P., Ezati, B.A., Bisaso, R., Hölttä, S., and Pekkola, E. (2014) Migrating a professional field of study in a multi-institutional partnership: facilitators' experience in the competence based curriculum development process. The Tuning Journal for Higher Education I(2), 405-427.

Teferra, D., \& Altbach, P. G. (2004). African higher education: Challenges for the 2Ist century. Higher Education, 47(I), 2I-50.

World Bank (20II).World Bank Group Education Sector Strategy 2020: Learning for All. Investing in People's Knowledge and Skills to Promote Development. Washington DC: World Bank. 